\title{
correspondence
}

\section{Developing countries need appropriate science policy}

SIR,- The eight problems regarding the relationship between researchers in the first and third worlds, summarised in Robert Walgate's article (2 March, pages 8-9), constitute very important challenges to the developing countries themselves. Contrary to the popular belief that research is an expensive ivory-tower activity, it is developing countries that must spend relatively more of their resources on research in order to accelerate their development.

Developing countries must establish and finance scientific policy bodies made up of local scientists, who are in the best position to interpret real development problems into the necessary scientific and technological requirements. Local scientists must not only carry out basic research, they must also act as focal points for the processes of transferring scientific knowledge towards solving development needs. They must not only assist their nations in defining development problems, but they must also be sympathetic to and guided by those development needs in organising their research activities.

One of the biggest drawbacks in developing countries is the lack of continuous and effective transfer of scientific knowledge to all people, especially to such key people as teachers who can be very effective in reaching the general public. There is a tendency for knowledge to remain a possession of the more educated, urban and industrial/commercial communities. Local scientists have a vital role to play in effecting this transfer of knowledge so that the creative potentials of people, including rural communities, can be enriched and facilitated for development.

It is in achieving all this that the assistance of the developed countries needs to be sincerely given. All research done in a developing country should make a definite contribution to the development of that country. This can only happen if the developing countries are assisted to have effective science policy bodies and scientists whose operational capabilities are enhanced and maintained through provision of adequate technical staffing and financial resources.

\section{Yours faithfully,} Joseph Maina Mungai

National Council for Science and Technology,

Nairobi, Kenya

\section{Dangers of 'dissident' correspondence}

SIR,-As a practising physicist with some personal contact with Russian scientists, I share the shock and horror which must be felt by everyone over the cruel severity of Orlov's sentence, and indeed his apparent lack of crime (in western terms) in the first place.

However, I fear that your encouragement (25 May, page 255) to western scientists to express their disgust to Soviet colleagues through the several channels of communication available to us may be seriously irresponsible in one regard. Y am concerned that to write to a Russian colleague on the subject of human rights and political dissention in the Soviet Union may invite upon that colleague official disapproval from the Soviet authorities. We cannot be sure of the extent of surveillance and censorship of incoming letters to Soviet scientists, but we can be sure that the Soviet bureaucracy would take a dim view, if they

did find out, of one of their scientists being involved in 'dissident'

correspondence with westerners. At the least we may be embroiling a friend or colleague in a political issue in which he or she does not wish to become involver, perhaps for very good personal or family reasons. Moreover, if the scientist to whom we write has travelled in the West previously the suspicion may arise that during his visits he has indulged in anti-Soviet discussions, and we may well be putting him on the black list as far as further travel to the West is concerned. And quite possibly in the extreme case we might be seriously putting at risk the safety or security of our colleagues or their families.

We cannot be sure, of course, that any of these things may happen. But although the treatment of dissidents like Orlov is atrocious, do we have any right to interfere and intrude in a self-righteous way into the personal lives of Russian scientific colleagues? There is an element of a blind 'crusading' or 'God on our side' attitude in doing this if we do not carefully investigate the ramifications and implications fully of such action.

For these reasons, and that of pure effectiveness, I believe that the best course of action is for those of us who are concerned about the issues raised by the Orlov case and others to encourage our official agencies, such as the Royal Society, the Institute of Physics and Anglo-Soviet organisations, to contact their counterparts in the USSR and the Soviet government about these travesties of human rights. In this connection I was encouraged to learn in an accompanying article that the Royal Society has already spoken out on the Orlov sentence. Yours faithfully,

Surbiton, Surrey, UK JOHN E. HARRIES

\section{Parkinson's Law in the Antarctic}

SIR,-While I agree that there is a general tendency for the number of administrators in a scientific organisation to grow, I believe that in developing a thesis it is incumbent upon the originator to use facts which he not only believes to be correct, but to ensure that those facts, when they are used for comparative purposes, are comparable in origin. This does not appear to be so in the case of the data used by Dr Moss in his letter (18 May, page 184). I can only speak with knowledge of one of the fourteen NERC component bodies, the British Antarctic Survey, for which he gives as total staff 337 -scientific staff 170-addresses one.

In examining these figures we need to determine the difference between administrators and non-scientific staff who are not administrators. Dr Moss appears to confuse the two. Ships' crews, aircrew, mechanics, radio operators, electricians, cooks and carpenters are certainly not administrators. The BAS staff in these categories number 127 . But since none of the scientific work in the Antarctic could be done without them, it is difficult to see how the statement "the number of administrators within a public organisation tends to increase irrespective of the amount of external work done by that organisation" can be said to apply.

If it is thought that it does, then their counterparts in an organisation working entirely in the UK, should also be included-wives, electricians, transport staff, mechanics, switchboard operators, cleaners, and indeed many others who in this country provide the services on which scientists depend. This would make a nonsense of his thesis. I therefore suggest that, in one case at least, his concept is based on comparing unlike with unlike.

Another factor with which much play is made is the number of 'addresses'; BAS being said to have one. In fact the survey has its headquarters in Cambridge, an office in the Falkland Islands and five Antarctic stations. It also runs two ships and two aircraft. The operation of all these, including their requirements for food, buildings and equipment in the field, are provided for by a total administrative staff of only 40.

I would say to Dr Moss, as regards the British Antarctic Survey,

'O most lame and impotent conclusion.

(Othello, Act ii, sc. 1.) Yours faithfully,

Cambridge, UK

V. E. Fuchs

\section{God's bonds}

SIR,--Why do nucleic acids have $3^{\prime} 5^{\prime}$ phosphodiester bonds? This question was resolved by Dhingra and Sarma in a recent issue of Nature (272, 798 (1978)).

Earlier, the irreplaceable late

Gordon Tomkins quipped (as quoted by Paul Sigler):

"Twos and fives are made by fools like you and me,

and only God can make a five and three".

Yours faithfully, HenRYK Eisenberg

Rehovot, Israel 